\title{
Signs for early diagnosis of heart failure in primary health care
}

This article was published in the following Dove Press journal:

Vascular Health and Risk Management

I3 September 201।

Number of times this article has been viewed

\author{
Dirk Devroey ${ }^{1,2}$ \\ Viviane Van Casteren' \\ 'Scientific Institute of Public Health, \\ Unit of Epidemiology, Brussels, \\ Belgium; ${ }^{2}$ Vrije Universiteit Brussel \\ (VUB), Department of Family \\ Medicine, Brussels, Belgium
}

Correspondence: Dirk Devroey Vrije Universiteit Brussel (VUB) Department of Family Medicine, Laarbeeklaan 103,

B- 1090 Brussels, Belgium

Tel +32 24774705

Fax +32 2477430 I

Email dirk.devroey@vub.ac.be
Objective: The current guidelines for the diagnosis of heart failure (HF) are based on studies of hospital-based patients. The aim of this study is to describe the symptoms, clinical signs, and diagnostic procedures confirming the diagnosis of HF in primary health care.

Materials/subjects and methods: Data were prospectively collected during a 2-year period by a nationwide network of sentinel practices. All adult patients without known HF, for which the diagnosis of HF was clinically suspected for the first time, were registered. When diagnosed, HF was confirmed after 1 month.

Results: 754 patients with a suspicion of HF were recorded. The diagnosis of HF was confirmed for $74 \%$ of the patients. The average age of the patients with confirmed HF was 77.7 years, and for those without HF 75.6 years $(P=0.018)$. From a logistic regression, breathlessness on exercise $(P<0.001)$, limitations of physical activity $(P=0.003)$, and orthopnea $(P=0.040)$ were the symptoms most associated with HF. The clinical signs most associated with HF, were pulmonary rales $(P<0.001)$, peripheral edema $(P<0.001)$, and raised jugular venous pressure $(P=0.039)$. An electrocardiogram was performed in $75 \%$ of the cases, blood analyses in $68 \%$, echocardiogram in $63 \%$, chest X-ray in $61 \%$, and determination of natriuretic peptides in $11 \%$ of the cases.

Conclusion: Many clinical signs may occur in patients with HF. However, the occurrence of peripheral edema, breathlessness on exercise, or pulmonary rales, are highly suggestive for HF when diagnosed in primary health care, as is the case in hospital-admitted patients. The diagnosis of HF was often left unconfirmed by an echocardiogram and/or an electrocardiogram.

Keywords: heart failure, primary health care, diagnostic clinical signs

\section{Introduction}

Heart failure (HF) is a common diagnosis in primary health care. It is becoming one of the main causes of morbidity and mortality in the Western world. ${ }^{1}$ Diagnosis of HF is related to a poor prognosis. In 1933, Sir Thomas Lewis emphasized in his textbook "Diseases of the Heart" that "the very essence of cardiovascular medicine is the recognition of early heart failure."2

The short- and long-term outcome for patients with HF is considered worse than for most malignant diseases. The risk of mortality increases more than three-fold with $\mathrm{HF}^{3}$ With the aid of the newest drugs and devices, the chances of survival for patients with HF have improved. However, the diagnosis of HF remains problematic in primary health care. Many definitions of HF have been used over the last 50 years. ${ }^{4}$ Most definitions emphasized the combination of symptoms of HF and clinical signs of fluid retention. ${ }^{5}$ According to the guidelines of the European Society of Cardiology 
(ESC), HF is defined as a clinical syndrome, in which patients have symptoms, as well as clinical signs, typical of HF. The need for objective evidence of a structural or functional abnormality of the heart at rest is also incorporated in this definition. $^{6}$

Almost all guidelines are based on evidence resulting from epidemiological and clinical studies, performed on hospital-based patients. ${ }^{4-6}$ Very little reliable data exists about the diagnostic procedures for patients who present with HF in primary health care. Because of the differences in the clinical presentation and the severity of HF in primary health care patients, as compared to hospital-based patients, it is likely that symptoms and clinical signs leading to the diagnosis of HF may differ between these patient groups.

The aim of this study is to describe the symptoms, clinical signs, and diagnostic procedures confirming the diagnosis of HF in primary health care.

\section{Materials and methods}

The Belgian network of sentinel practices

The data for this study were collected by the Belgian network of sentinel practices. This network serves as a reliable source on the surveillance of morbidity in Belgium, and has been operating with similar methods since $1979 . .^{7-9}$ The network has already been tested and proven effective as a surveillance system. ${ }^{9-11}$ Similar networks are currently applied in many other countries. ${ }^{12,13}$ The sentinel practices are distributed evenly over the Belgian territory by means of a cluster analysis, based on epidemiological criteria. ${ }^{7,8}$ The network of sentinel practices consists of family physicians who, with respect to age and gender, are representative of family physicians in Belgium. The yearly adult sentinel population during the registration period was estimated to be 143,705 or almost $1.8 \%$ of the Belgian adult population.

Registration by the Belgian Network of Sentinel General Practices has been approved by an ethical committee. There was no specific ethical approval necessary for the present study, because it concerned a registration of the usual care provided without interventions.

\section{Case ascertainment}

The data were collected during a 2-year period from 178 sentinel practices, who participated in the registrations at least 26 weeks a year. The participating family physicians were asked to register all their adult patients without known $\mathrm{HF}$, for whom a diagnosis of HF was suspected for the first time. The observations were initially registered on the weekly registration form, together with other themes in the observation program. The possibility of HF was based on the patient's symptoms and clinical signs.

For every recorded patient, the participating family physician was sent an additional in-depth questionnaire 1 month after the initial registration. The physicians then provided additional or more detailed information on diagnostic criteria and complementary examinations, on which the final diagnosis was based. Examples of additional or more detailed information are: clinical improvement with proper therapy, specialist consultation or objective evidence of cardiac anomalies on echocardiography, or chest X-ray.

\section{Data management and statistical analysis}

Data were entered weekly at the Scientific Institute of Public Health. The data analyses for this study were performed using SPSS (v 17.0; SPSS Inc, Chicago, IL). Univariate association between diagnosis of HF and symptoms/clinical signs was tested by means of chi square tests. Fisher's exact test was used when less than ten observations were concerned. Multivariate analyses were performed with backward stepwise logistic regression, to look at the association between the diagnosis of HF and symptoms/clinical signs. Also the sensitivity, specificity, positive predictive value (PPV), and the negative predictive value (NPV) of different symptoms and clinical signs were calculated.

\section{Results}

\section{Characteristics of the population}

In total, 754 patients were suspected to have newly diagnosed HF during the 2 years of the registration. The diagnosis of HF was confirmed for 557 patients (or $74 \%$ of all recorded patients) after 1 month. In total, $56 \%$ of the patients with confirmed $\mathrm{HF}$ were female and $44 \%$ were male. The patients without HF were 51\% male and $49 \%$ were female. The average age of the patients with confirmed HF was 77.7 years $(\mathrm{SD}=10.3$; range 26-101) and for those without $\mathrm{HF}$ 75.6 years $(\mathrm{SD}=11.2$; range $30-100 ; P=0.018)$.

\section{Symptoms and clinical signs}

The most common symptoms among the patients with HF were breathlessness on exercise $(67 \%)$ and limitations of physical activity (60\%). All symptoms occurred significantly more often among patients with HF, as compared to those without HF (Table 1). All symptoms had fair or good specificity, but only two had good sensitivity. The most common symptoms among those without HF (breathlessness 
Table I Symptoms and clinical signs for patients with and without heart failure

\begin{tabular}{|c|c|c|c|c|c|c|c|}
\hline & $\begin{array}{l}\text { Heart failure } \\
(n=557) \\
n(\%)\end{array}$ & $\begin{array}{l}\text { No heart failure } \\
(n=197) \\
n(\%)\end{array}$ & $P$ value & Sens & Spec & PPV & NPV \\
\hline Nocturnal dyspnea & $143(26)$ & $22(11)$ & $<0.001$ & 0.26 & 0.89 & 0.87 & 0.30 \\
\hline Orthopnea & $258(46)$ & $43(22)$ & $<0.00 \mathrm{I}$ & 0.46 & 0.78 & 0.86 & 0.34 \\
\hline Limitations of physical activity & $334(60)$ & $72(37)$ & $<0.00 \mathrm{I}$ & 0.60 & 0.64 & 0.82 & 0.36 \\
\hline Breathlessness on exercise & $372(67)$ & $74(38)$ & $<0.00 \mathrm{I}$ & 0.67 & 0.62 & 0.83 & 0.40 \\
\hline Fatigue & $258(46)$ & $55(28)$ & $<0.001$ & 0.46 & 0.72 & 0.82 & 0.32 \\
\hline Other symptoms & $65(12)$ & $25(13)$ & 0.70 & 0.12 & 0.87 & 0.72 & 0.26 \\
\hline Third heart sound & $58(10)$ & $6(3)$ & 0.001 & 0.10 & 0.97 & 0.91 & 0.28 \\
\hline Cardiac murmurs & $123(22)$ & $25(13)$ & 0.004 & 0.22 & 0.87 & 0.83 & 0.28 \\
\hline Pleural effusion & $128(23)$ & $22(\mathrm{II})$ & $<0.00 \mathrm{I}$ & 0.23 & 0.89 & 0.85 & 0.29 \\
\hline Pulmonary rales & $344(62)$ & $64(33)$ & $<0.001$ & 0.62 & 0.68 & 0.84 & 0.38 \\
\hline Raised jugular venous pressure & $145(26)$ & $19(10)$ & $<0.001$ & 0.26 & 0.90 & 0.88 & 0.30 \\
\hline Hepatomegaly & $87(16)$ & $8(4)$ & $<0.001$ & 0.16 & 0.96 & 0.92 & 0.29 \\
\hline Peripheral edema & $381(68)$ & $70(36)$ & $<0.001$ & 0.68 & 0.65 & 0.85 & 0.42 \\
\hline Other clinical signs & $89(16)$ & $20(10)$ & 0.046 & 0.16 & 0.90 & 0.82 & 0.27 \\
\hline
\end{tabular}

Abbreviations: PPV, positive predictive value; NPV, negative predictive value.

on exercise [38\%], limitation of physical activity [37\%], and fatigue [28\%]) also had fair or good specificity and sensitivity for HF.

During physical examination of the patients with HF, peripheral edema was observed in $68 \%$, and pulmonary rales in $62 \%$ of the cases. All clinical signs occurred significantly more often among patients with HF, as compared to those without HF (Table 1). All clinical signs had fair or good specificity but only two had good sensitivity. The most common clinical signs among those without HF (peripheral edema [36\%] and pulmonary rales [33\%]) also had good specificity and sensitivity for HF.

For the patients with HF, an electrocardiogram was performed in $75 \%$, blood analyses in $68 \%$, echocardiogram in $63 \%$, chest X-ray in $61 \%$, and determination of natriuretic peptides in $11 \%$ of the cases. All investigations were performed significantly more often among patients with HF as compared to those without diagnosed HF.

To determine the symptoms and clinical signs with the highest association with the diagnosis of HF, we built a model on the basis of patient characteristics, using backward stepwise logistic regression, with diagnosis of HF after 1 month as a dependent variable (Table 2). Breathlessness on exercise $(P<0.001)$, pulmonary rales $(P<0.001)$, peripheral edema $(P<0.001)$, limitation of physical activity $(P=0.003)$, raised jugular venous pressure $(P=0.039)$, and orthopnea $(P=0.040)$ had the highest association with the diagnosis of HF.

Finally, the sensitivity, specificity, PPV, and NPV were calculated for all symptoms and clinical signs

Table 2 Logistic regression stepwise backwards (last step) with the diagnosis of heart failure as independent variable and the different symptoms and clinical signs as dependent variables

\begin{tabular}{|c|c|c|c|c|c|c|c|}
\hline & \multicolumn{2}{|c|}{$\begin{array}{l}\text { Unstandardized } \\
\text { coefficients }\end{array}$} & \multirow{2}{*}{$\begin{array}{l}\text { Standard } \\
\text { coefficients } \\
\text { Beta }\end{array}$} & \multirow[t]{2}{*}{$\boldsymbol{t}$} & \multirow[t]{2}{*}{$P$ value } & \multicolumn{2}{|c|}{$95 \%$ confidence interval for B } \\
\hline & B & Standard error & & & & Lower bound & Upper bound \\
\hline Orthopnea & 0.07 & 0.03 & 0.08 & 2.05 & 0.040 & 0.01 & 0.13 \\
\hline Limitations of physical activity & 0.09 & 0.03 & 0.10 & 3.02 & 0.003 & 0.03 & 0.15 \\
\hline Breathlessness on exercise & 0.12 & 0.03 & 0.14 & 3.90 & $<0.001$ & 0.06 & 0.18 \\
\hline Third heart sound & 0.10 & 0.05 & 0.06 & 1.94 & 0.053 & -0.01 & 0.20 \\
\hline Pulmonary rales & 0.14 & 0.03 & 0.15 & 4.26 & $<0.001$ & 0.07 & 0.20 \\
\hline Raised jugular venous pressure & 0.08 & 0.04 & 0.07 & 2.07 & 0.039 & 0.01 & 0.15 \\
\hline Peripheral edema & 0.20 & 0.03 & 0.22 & 6.54 & $<0.001$ & 0.14 & 0.26 \\
\hline Others clinical signs & 0.11 & 0.04 & 0.09 & 2.99 & $<0.001$ & 0.03 & 0.19 \\
\hline
\end{tabular}

Notes: Logistic regression within the first step gender, age, nocturnal dyspnea, orthopnea, limitations of physical activity, breathlessness on exercise, fatigue, other symptoms, third heart sound, cardiac murmurs, pleural effusion, pulmonary rales, raised jugular venous pressure, hepatomegaly, peripheral edema, and other clinical signs. 
(Table 1). Peripheral edema, breathlessness on exercise, and pulmonary rales had fair sensitivity and specificity for the prediction of HF.

Many models of combinations of symptoms and clinical signs were tested for their sensitivity and specificity. The combination of peripheral edema and breathlessness on exercise and pulmonary rales had good specificity ( $\operatorname{spec}=0.89)$ to detect HF, but low sensitivity ( $\operatorname{sens}=0.31$ ). The occurrence of peripheral edema or breathlessness on exercise or pulmonary rales had good sensitivity ( $\operatorname{sens}=0.96)$ but moderate specificity $(\operatorname{spec}=0.41)$ for the prediction of HF.

\section{Diagnosis for patients without heart} failure

For $26 \%$ of the patients, the diagnosis of HF was not confirmed after 1 month. Airway infections or obstructive airway diseases were the most common diagnosis in this group $(25 \%)$. Other common diagnoses for patients without HF were peripheral edema caused by venous insufficiency (21\%), malaise (15\%), ischemic cardiac disease or arrhythmia (9\%), non-cardiac chest pain $(6 \%)$, and various other diseases $(24 \%)$.

\section{Discussion}

Peripheral edema, breathlessness on exercise, and pulmonary rales had the best sensitivity and specificity to detect HF. One in four patients with a suspicion of HF did not receive an electrocardiogram and an echocardiogram was performed on only two in three patients. All diagnostic procedures were performed significantly more often among patients for whom the diagnosis of HF was made, as compared to those for whom the diagnosis of HF was not made. It is possible that in the group without HF, more diagnoses of HF could have been made if more diagnostic tests had been performed.

\section{Belgian Network of Sentinel General Practitioners}

One of the most important characteristics of the Belgian Network of Sentinel General Practitioners (GPs) is its stability in terms of participating GPs. The GPs are highly motivated to monitor various diseases over a period of several years. They have not been selected on the basis of a specific interest in the diagnosis or treatment of HF.

Detailed information concerning provided care is not always available from medical records in Belgium. Therefore, direct registration by GPs has important added value. Also, the network offers the opportunity to monitor a representative sample of the entire population. For several conditions, such as suicide and the incidence and mortality of stroke and cancer, comparisons with the data from the National Institute for Statistics have shown that the Belgian Network of Sentinel General Practitioners provides information that is representative for the entire Belgian population..$^{9,14,15}$ The choice of GPs is clinically relevant as they represent the pivotal figures involved in the early diagnosis in Western societies and the subsequent follow-up of HF patients.

In many epidemiological studies, data collection is retrospective. For example, HF was identified in the Framingham Heart Study by examining individuals within a cohort and at certain intervals. ${ }^{16}$ However, in the Helsinki Aging Study and in some other more recent registrations, data were accessed by population-based surveillance systems in which individuals developing HF were prospectively included. ${ }^{17-19}$ Our registration also uses a prospective registration of $\mathrm{HF}$, which has the advantage that incident cases may be fully characterized at the time of the diagnosis.

The retrospective recall bias found in other retrospective research designs, will be limited in the registrations by our network, because the weekly registrations leave little time between the onset of $\mathrm{HF}$ and registration. ${ }^{20,21}$

Unfortunately, the surveillance system by the Sentinel Network also has some weaknesses. Time-consuming questions were avoided to keep the registration form simple. For this type of registration, in-depth research of more complicated aspects of disease and health conditions is not possible. $^{22}$

\section{Diagnosis of heart failure}

Currently, no universal definition of HF exists. This lack of uniform definition hampers the comparison of symptoms and signs for HF in different studies. Most patients with HF seek medical attention with nonspecific symptoms and clinical signs. Therefore, the early diagnosis of HF requires good medical history and careful physical examination, including observation, palpation, and auscultation. ${ }^{23}$ Tiredness, fatigue, and breathlessness are very common complaints. Assessing these symptoms among the elderly requires training and experience. $^{24}$

From our logistic regression analyses, the presence of pulmonary rales, peripheral edema, and raised jugular venous pressure are highly associated with the diagnosis of HF. The symptoms as well as the clinical signs of HF are difficult to interpret. Almost all symptoms and clinical signs have good specificity but sensitivity is only good for breathlessness on exercise, pulmonary rales, peripheral edema, and limitation 
of physical activity. The key symptoms such as tiredness, fatigue, and breathlessness are very nonspecific among elderly and obese patients. In these cases, the diagnosis of HF needs to be confirmed by more objective tests with an assessment of cardiac function.

The ESC recommends a number of investigations to confirm the diagnosis of $\mathrm{HF}^{6}$ Patients for whom HF is suspected, should not only have a thorough clinical examination but also an electrocardiogram, a chest X-ray, and an echocardiogram. These diagnostic procedures were not always performed in our registration. The participating family physicians were free to perform these procedures, if they thought they might contribute to the diagnosis.

A strength of our study is that the diagnosis of HF was confirmed after 1 month, giving the family physicians the opportunity for further investigations, and excluding most of the inaccurate diagnoses. In our study, the diagnosis of HF was confirmed after 1 month for $74 \%$ of all recorded patients. This is remarkably better than a study from the UK, where for $70 \%$ of patients with a primary care diagnosis of $\mathrm{HF}$, the diagnosis was not confirmed. ${ }^{25}$ However, in this kind of study, the proportion of patients with confirmed HF strongly depends on the study sample.

On the other hand, in primary health care, most of the diagnostic procedures are not very specific for HF. Chest $\mathrm{X}$-ray permits differential diagnoses with other causes of dyspnea, but has little power to exclude HF. Echocardiography provides insight into the function of several parts of the heart, but for many years there was doubt about the usefulness of echocardiography to confirm or exclude HF. ${ }^{26}$ Nowadays, more evidence exists regarding the prognostic importance of echocardiography in patients with "borderline" ventricular function. ${ }^{27} \mathrm{~A}$ normal concentration of natriuretic peptides makes the diagnosis of HF unlikely, but increased levels have only little predictive value for HF.

\section{Conclusion}

From this 2-year prospective registration in primary health care, we conclude that many symptoms and clinical signs may appear among patients with HF. Similar to the results of the hospital-based studies, the study shows that peripheral edema, breathlessness on exercise, and pulmonary rales are the most reliable symptoms and clinical signs for the diagnosis of HF in primary health care. To determine these specific diagnostic characteristics, all patients in primary health care with a suspicion of HF need a thorough medical history taken, and careful physical examination including observation, palpation, and auscultation. The occurrence of peripheral edema, breathlessness on exercise, or pulmonary rales in primary health care is highly suggestive for HF and needs to be evaluated by specific diagnostic procedures evaluating cardiac function. Too many patients with suspected HF don't receive an electrocardiogram or an echocardiogram.

\section{Acknowledgments}

The authors thank all participating family physicians for the registration of patients, Karolien Vantomme for the comments on the manuscript and David Proot for English language copy editing. The Flemish and Walloon government fund the Belgian sentinel stations network.

\section{Disclosure}

The authors report no conflicts of interest in this work.

\section{References}

1. McMurray JJV, Stewart S. The burden of heart failure. Eur Heart J. 2002;4(Suppl D):D50-D58.

2. Lewis T. Diseases of the Heart. London, UK: MacMillan; 1933.

3. Bonneux L, Barendregt JJ, Meeter K, Bonsel GJ, van der Maas PJ. Estimating clinical morbidity due to ischemic heart disease and congestive heart failure: the future rise of heart failure. Am J Public Health. 1994;84(1):20-28.

4. Poole-Wilson PA. History, definition, and classification of heart failure. In: Poole-Wilson PA, Colucci WS, Massie BM, Chatterjee K, Coats AJS, editors. Heart Failure: Scientific Principles and Clinical Practice. New York: Churchill Livingstone; 1997:269-277.

5. National Clinical Guideline Centre. Chronic heart failure: the management of chronic heart failure in adults in primary and secondary care. London: National Clinical Guideline Centre; 2010. Available from: http://guidance.nice.org.uk/CG108/Guidance/pdf/English. Accessed on December 4, 2010.

6. Task Force for Diagnosis and Treatment of Acute and Chronic Heart Failure 2008 of European Society of Cardiology; Dickstein K, Cohen-Solal A, Filippatos G, et al. ESC Guidelines for the diagnosis and treatment of acute and chronic heart failure 2008: the Task Force for the Diagnosis and Treatment of Acute and Chronic Heart Failure 2008 of the European Society of Cardiology. Developed in collaboration with the Heart Failure Association of the ESC (HFA) and endorsed by the European Society of Intensive Care Medicine (ESICM). Eur Heart J. 2008;29(19):2388-2442.

7. Stroobant A, Van Casteren V, Thiers G. Surveillance systems from primary-care data: surveillance through a network of sentinel general practitioners. In: Eylenbosch WJ, Noah D, editors. Surveillance in Health and Disease. Oxford, UK: Oxford University Press; 1988:62-74.

8. Lobet MP, Stroobant A, Mertens R, et al. Tool of validation of the network of sentinel general practitioners in the Belgian health care system. Int J Epid. 1987;16(4):612-618.

9. Devroey D, Van Casteren V, Buntinx F. Registration of stroke through the Belgian sentinel network and factors influencing stroke mortality. Cerebrovasc Dis. 2003;16(3):272-279.

10. Van den Block L, Deschepper R, Bilsen J, Van Casteren V, Deliens L. Transitions between care settings at the end of life in Belgium. JAMA. 2007;298(14):1638-1639.

11. Grob PR. A morbidity recording system for primary health care. In Leaverton PE, editor. Environmental Epidemiology. New York: Praeger Publishers; 1982:131-139.

12. Deckers JG, Paget WJ, Schellevis FG, Fleming DM. European primary care surveillance networks: their structure and operation. Fam Pract. 2006;23(2):151-158. 
13. Van Casteren V. Inventory of Sentinel Health Information Systems with general practitioners in the European Community. Situation up to March 1990. Brussels, Belgium: IHE; 1991:97.

14. Boffin N, Bossuyt N, Van Casteren V. Survey profile of the Sentinel General Practitioners in 2005 and their evolution since 2001. [Het profiel van de peilartsen inn 2005 en hun evolutie sinds 2001]. Scientific Institute of Public Health Belgium; Department of Epidemiology; 2007. Dutch.

15. Van Casteren V, Tafforeau J, Van Oyen H. Suicide and attempted suicide reported by general practitioners in Belgium, 1990-1991. Acta Psychiatr Scand. 1993;87(6):451-455.

16. Ho KKL, Pinsky JL, Kannel WB, Levy D. The epidemiology of heart failure: the Framingham Study. J Am Coll Cardiol. 1993;22 (4 Suppl A):6A-13A.

17. Hedberg P, Lonnberg I, Jonason T, Nilsson G, Pehrsson K, Ringqvist I. Left ventricular systolic dysfunction in 75-year-old men and women; a population-based study. Eur Heart J. 2001;8(22):676-683.

18. Kupari M, Lindroos M, Iivanainen AM, Heikkila J, Tilvis R. Congestive heart failure in old age: prevalence, mechanisms and 4-year prognosis in the Helsinki Ageing Study. J Intern Med. 1997;241(5):387-394.

19. Mosterd A, Hoes AW, de Bruyne MC, et al. Prevalence of heart failure and left ventricular dysfunction in the general population; The Rotterdam Study. Eur Heart J. 1999;20(6):447-455.
20. Van der Heide A, Deliens L, Faisst K, et al; EURELD consortium. End-of-life decision-making in six European countries: descriptive study. Lancet. 2003;362(9381):345-350.

21. Teno JM. Measuring end-of-life care outcomes retrospectively. J Palliat Med. 2005;8(Suppl 1):S42-S49.

22. Fleming DM, Schellevis FG, Paget WJ. Health monitoring in sentinel practice networks: the contribution of primary care. Eur J Public Health. 2003;13(3 Suppl):80-84.

23. Spiteri MA, Cook DG, Clarke SW. Reliability of eliciting physical signs on examination of the chest. Lancet. 1988;1(8590):873-875.

24. Green CP, Porter CB, Bresnahan DR, Spertus JA. Development and evaluation of the Kansas City Cardiomyopathy Questionnaire: a new health status measure for heart failure. J Am Coll Cardiol. 2000; 35(5):1245-1255.

25. Cowie MR, Wood DA, Coats AJ, et al. Incidence and aetiology of heart failure. A population-based study. Eur Heart J. 1999;20(6):421-428.

26. McCall D. Recognition and management of asymptomatic patients with left ventricular dysfunction. Am J Cardiol. 1992;69(18):130G-139G.

27. Wang TJ, Evans JC, Benjamin EJ, Levy D, LeRoy EC, Vasan RS. Natural history of asymptomatic left ventricular systolic dysfunction in the community. Circulation. 2003;108(8):977-982.
Vascular Health and Risk Management

\section{Publish your work in this journal}

Vascular Health and Risk Management is an international, peerreviewed journal of therapeutics and risk management, focusing on concise rapid reporting of clinical studies on the processes involved in the maintenance of vascular health; the monitoring, prevention and treatment of vascular disease and its sequelae; and the involvement of

\section{Dovepress}

metabolic disorders, particularly diabetes. This journal is indexed on PubMed Central and MedLine. The manuscript management system is completely online and includes a very quick and fair peer-review system, which is all easy to use. Visit http://www.dovepress.com/ testimonials.php to read real quotes from published authors. 